\title{
Parental effects influence life history traits and covary with an environmental cline in common frog populations
}

\author{
Piotr K. Rowiński ${ }^{1}$ - Anssi Laurila ${ }^{2} \cdot$ Karl Gotthard $^{1} \cdot$ Will Sowersby $^{1} \cdot$ Martin I. Lind $^{2} \cdot$ Alex Richter-Boix $^{2}$. \\ Simon Eckerström-Liedholm ${ }^{1} \cdot$ Björn Rogell ${ }^{1,3}$
}

Received: 6 December 2018 / Accepted: 3 April 2020 / Published online: 10 April 2020

(c) The Author(s) 2020

\begin{abstract}
Across latitudinal clines, the juvenile developmental rates of ectotherms often covary with the length of the growing season, due to life-history trade-offs imposed by the time-constrained environments. However, as the start of the growing season often varies substantially across years, adaptive parental effects on juvenile developmental rates may mediate the costs of a delayed season. By employing a meta-analysis, we tested whether larval developmental rates across a latitudinal cline of the common frog (Rana temporaria) are affected by fluctuating onsets of breeding, across years. We predicted that larval developmental rate will be inversely related to the onset of breeding, and that northern populations will be more prone to shorten their developmental rate in response to late breeding, as the costs of delayed metamorphosis should be highest in areas with a shorter growing season. We found that the larval period of both northern and southern populations responded to parental environmental conditions to a similar degree in absolute terms, but in different directions. In northern populations, a late season start correlated with decreased development time, suggesting that the evolution of parental effects aids population persistence in time-constrained environments. In southern populations, late season start correlated with increased development time, which could potentially be explained as a predator avoidance strategy. Our findings suggest that local ecological variables can induce adaptive parental effects, but responses are complex, and likely trade-off with other ecological factors.
\end{abstract}

Keywords Maternal effects $\cdot$ Phenology $\cdot$ Local adaptation $\cdot$ Temperature $\cdot$ Trade-offs

\section{Introduction}

Across taxa, environmental parental effects occur when environmental factors experienced by parents affect the phenotype of their offspring, independent of the parent genetic contribution (Bernardo 1996; Mousseau and Fox 1998a). Environmentally induced parental effects may be adaptive, if they allow parents to modify offspring phenotypes to increase offspring fitness, in response to reliable environmental cues, such as photoperiod or temperature (Rossiter 1996; Marshall and Uller 2007; Uller et al. 2013). Consequently, parental effects are considered to be an important part of evolutionary processes (Kirkpatrick and Lande 1989; Mousseau and Fox 1998b; Räsänen and Kruuk 2007; Mousseau et al. 2009). However, relatively few studies have clearly demonstrated the adaptive value of parental effects (Uller et al. 2013). Potentially due to the subtle nature of parental effects, especially if within generational environmental influences dominate offspring phenotypes, in comparison to between generational influences (Uller et al. 
2013; but see also Donelan and Trussell 2018). Moreover, adaptive maternal effects are expected to evolve when environmental conditions differ across generations, when there are reliable cues about offspring environment, and if the cost of cue detection by the offspring is low, and if there is no or low levels of intergenerational conflict to maximize fitness (Mousseau and Fox 1998b; Marshall and Uller 2007; Kuijper and Hoyle 2015; Dury and Wade 2019). However, despite clear theoretical predictions for parental effects to evolve in response to local environmental conditions, there is limited empirical knowledge on the evolution of parental effects across varying environmental conditions (but see Dey et al. 2016; Lind et al. 2019).

One situation where maternal effects have been suggested as a key adaptive trait, is across environmental clines (Mousseau and Dingle 1991; Johnston and Leggett 2002). Across environmental clines, developmental time-constraints often occur at higher latitudes, and altitudes, or with low precipitation levels, which tend to select for localized adaptation (Berven 1982; Laugen et al. 2003; Rogell et al. 2009; Eckerström-Liedholm et al. 2017). For example, in ectotherms, low temperatures decrease the activity of biochemical and physiological processes (Zuo et al. 2012), resulting in slow developing phenotypes that risk failing to complete their life cycle, or to attain a size necessary to survive winter. As these plastic responses incur costs, natural selection often selects on higher intrinsic developmental rates to counteract the disadvantageous plastic responses induced by low temperatures (e.g., "counter-gradient variation", Conover and Schultz 1995). Counter-gradient variation has been reported in a wide variety of ectotherms, such as fish, amphibians, reptiles, mollusks, and insects (e.g., Conover and Present 1990; Laugen et al. 2003; Du et al. 2010; Li et al. 2018; Trussell 2002; Arnett and Gotelli 1999; but see also Tang et al. 2017). Why all populations do not always grow fast, has been attributed to life-history trade-offs caused by ecological (Laurila et al. 2006, 2008) or physiological factors (Conover and Present 1990; Levinton 1983). For example, along a latitudinal gradient of common frog (Rana temporaria) populations, intrinsic developmental rate increases with increasing latitude (Laugen et al. 2003). However, the faster development of northern $R$. temporaria entails costs, such as the requirement for higher levels of risk-taking behaviors necessary for obtaining the resources to fuel fast development, which in turn increases mortality risk, by increasing exposure to predators (Laurila et al. 2006, 2008). In addition, individuals with high growth rates are expected to have higher energetic requirements for bodily maintenance (Conover and Present 1990), and may therefore be more severely affected by suboptimal food availability, compared to individuals with slower growth (Levinton 1983). In R. temporaria, tadpoles from northern populations indeed need higher-quality food to realize their developmental potential, and they also have more efficient digestion than tadpoles from southern populations (Liess et al. 2015).

The existence of counter-gradient variation implies that time-limitations select on the developmental rates of ectotherms (Palo et al. 2003; Richter-Boix et al. 2010). Importantly, time-limitations may occur due to spatial or temporal variation in temperature, which influences length of the growing season. In such cases, adaptive parental effects, in addition to phenotypic plasticity, may allow parents to match the phenotypes of their offspring to the conditions experienced under each specific year. Indeed, earlier studies have shown that an experimental delay in parental reproduction, induces presumably adaptive parental effects in the moor frog (Rana arvalis), by decreasing larval periods, and by increasing growth rate and mass at metamorphosis (RichterBoix et al. 2014; Orizaola et al. 2016). Further, northern populations of $R$. temporaria shortened larval development during a late breeding season, in comparison to an earlier breeding season (Orizaola et al. 2013), while more southern populations increased their mass at metamorphosis and growth rate when their reproduction was postponed artificially (Lindgren and Laurila 2010). However, to assess the importance of these parental cues, under natural conditions, a broader investigation is required, spanning multiple years and populations. In addition, as parental effects presumably evolve as a means to cope with variation in time-constrained conditions, it seems likely that parental effects should be contingent on climate-related spatial clines (Mousseau and Dingle 1991; Orizaola et al. 2013; Richter-Boix et al. 2014). In areas with only a short window of opportunity for larval development, any costs incurred by either fast development or growth (Johansson et al. 2001; Janssens and Stoks 2018) are likely to be outweighed by the benefits of reaching a specific body size before the end of the growing season. Therefore, time-constrained northern populations may be more prone to display adaptive parental effects by shortening development during breeding seasons that begin late. Alternatively, northern populations may already be at the limits of their physiological capacity for fast development, leaving little scope for any additional parental effects to influence developmental rates (Lankford et al. 2001; Gillooly et al. 2002).

Here, using published data, we tested whether the expression of adaptive parental effects in respect to delayed reproduction is latitude-dependent in $R$. temporaria populations along Sweden (between latitudes of $55^{\circ} \mathrm{N}$ and $69^{\circ}$ $\mathrm{N}-1500 \mathrm{~km}$ across). We investigate how the timing of reproduction influences the expression of paternal effects on populations along an environmental cline, by analyzing 11 data-sets, where either breeding adult frogs were captured for laboratory crosses or eggs were collected immediately after been laid in the wild. The studies used in this metaanalysis, controlled for any external environmental cues 
by rearing larvae under a common-garden design, which ensured that any observed changes in larval life history traits were due to parental, and not offspring, environmental conditions. We tested if the length of the larval period was affected by breeding delay (difference between onset of spring and mean onset of spring) during the period prior to breeding. We predicted that (1) a later induction of breeding (onset of spring) should decrease length of growing season, and hence correlate with increased rates of larval development, and that (2) this response should be stronger in northern populations, as the costs of delayed metamorphosis should be highest in areas with short growing season.

\section{Materials and methods}

\section{Study species}

Rana temporaria is a common and wide-spread anuran in Europe, occurring in a variety of habitats, including tundra, forests, swamps, peatlands, fields, steppe and gardens (Kuzmin et al. 2009). The onset of breeding occurs early in the spring after the ice melts, and depends on both temporal (temperature) and spatial (latitude and altitude) climaterelated conditions (Phillimore et al. 2010). Rana temporaria populations have been extensively studied across latitudinal gradient in Sweden and northern Finland during the last 20 years (Table 1). See Online Resource 1 for more detailed species information.

\section{Data}

We searched for published studies, in which either freshly laid eggs or reproducing adults were collected, across Sweden and northern Finland. In total, data for $R$. temporaria were collected over 11 years between 1998 and 2009, from 57 sampling occasions at 26 different populations (breeding ponds), located between latitudes $55^{\circ} \mathrm{N}$ and $69^{\circ} \mathrm{N}$. Hence, in our study, each data point refers to a specific year and population sampling location. In total, we collected 11 data sets from 14 published studies (Table 1). In these studies, either parents were captured at breeding sites, and subsequently artificially crossed to produce offspring or alternatively, freshly laid eggs were collected in the wild and brought to the laboratory (Table 1). All eggs and larvae were then raised under standardized laboratory conditions until metamorphosis, and larval period, mass at metamorphosis and growth rate were all estimated (See Online Resource 1 for more details on data collection and calculation). All studies included in this analysis were either conducted at Uppsala University or at Umeå University in Sweden (See Table 1 and Fig. S2, Online Resource 2), and all larvae were kept under relatively similar conditions. In short, the larvae were raised in plastic containers (see Table 1 for details), fed ad-libitum with spinach or commercial fish flakes and rabbit pellets, kept at temperatures of $18-22{ }^{\circ} \mathrm{C}$, photoperiod of $16 \mathrm{~h}$ light $/ 8 \mathrm{~h}$ dark to $18 \mathrm{~h}$ light $/ 6 \mathrm{~h}$ dark, and without any cues from the external natural environment. The lack of cues from the natural environment was especially important, as conditions like temperature, photoperiod, and food variation can influence larval development rates.

\section{Variables of interest}

We were primarily interested in larval period, measured as the number of days between Gosner stage 25 (disappearance of gills) and 42 (emergence of forelimbs) (Gosner 1960), as this variable has the strongest connection to our prediction, that decreased length of growing season correlate with increased rates of larval development. Although mass at metamorphosis and growth rate (measured as the ratio between mass at metamorphosis and larval period) would also be interesting to investigate, unfortunately there were only limited observations for each of the latitudes (between 2 and 10) that reported both mass at metamorphosis, or growth rate, and their standard errors. In addition, we obtained data on two predictors: (1) reproductive delay the period between the mean first day of spring for a given location and reproductive event in the parental generation; the first day of spring is the first of seven consecutive days with average temperatures over $0{ }^{\circ} \mathrm{C}$, based on 1961-1990 average (SMHI 2017, see Online Resource 2, Fig. 2S); (2) latitude with four levels corresponding to four latitudinal groups, ordered from: southern $\left(55^{\circ} \mathrm{N}-57^{\circ} \mathrm{N}, n=14\right)$, mid-southern $\left(59^{\circ} \mathrm{N}-61^{\circ} \mathrm{N}, n=2\right)$, mid-northern $\left(63^{\circ} \mathrm{N}-64^{\circ} \mathrm{N}, n=28\right)$, to northern $\left(67^{\circ} \mathrm{N}-70^{\circ} \mathrm{N}, n=15\right)$ (see Fig. S2), as the populations of $R$. temporaria were sampled across a latitudinal gradient in Sweden and northern Finland (Online Resource 2, Fig. S2). There were only two observations from midsouthern populations (Fig. S2), so these two data points were not used in the analysis. To account for any differences in experimental procedures between studies, we included laboratory location, laboratory temperature, photoperiod, food, and larval density as additional predictors in our analyses.

\section{Models}

\section{Bayesian models}

We used Bayesian mixed-effect models, with the mean larval period for a given population in each study as a single response data point. A Gaussian error distribution was assumed in the model, and this assumption was visually confirmed from plots of the data. Following a meta-analytical approach, sampling error variance of the estimated mean was implemented in the model, calculated as the squared 


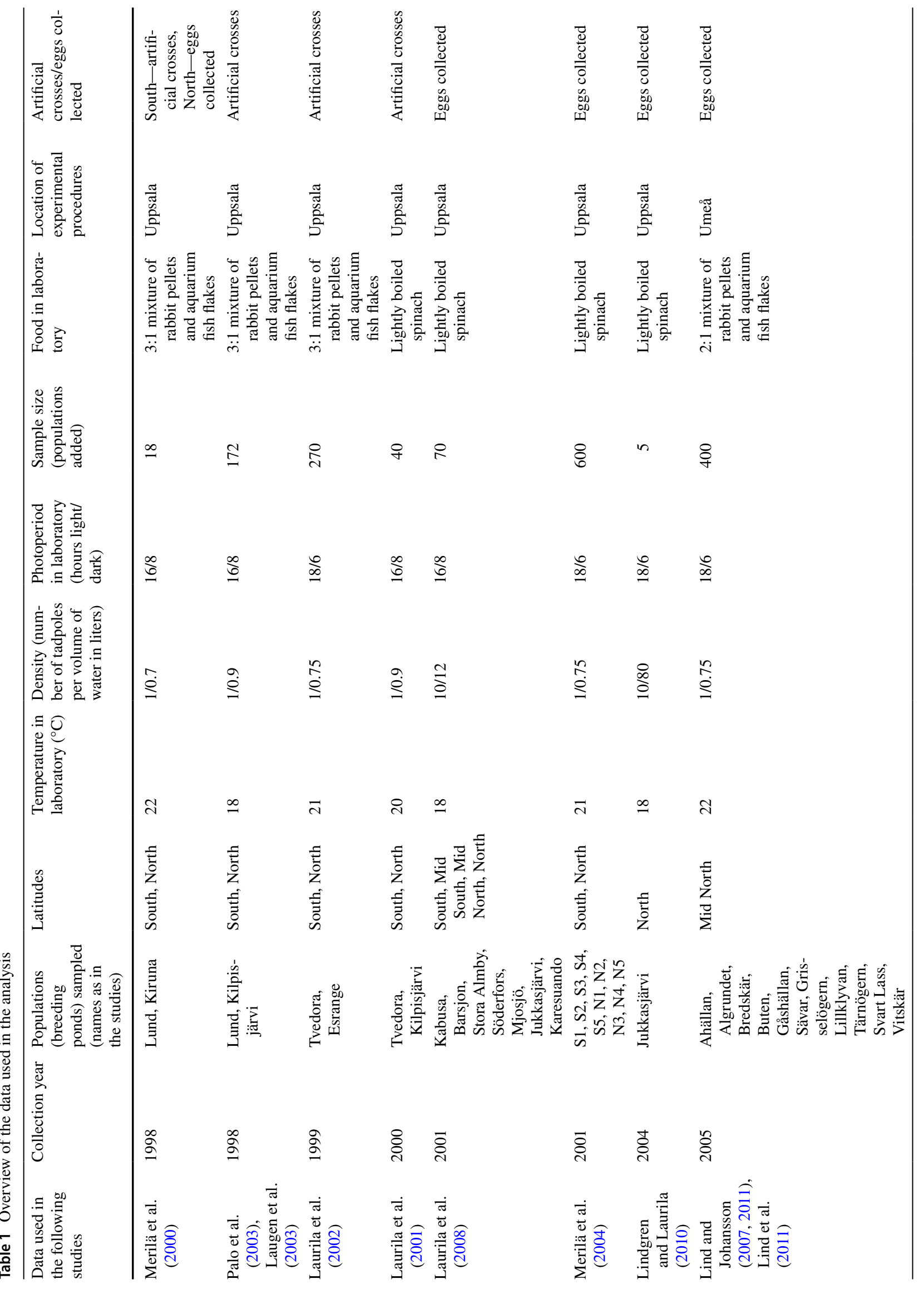




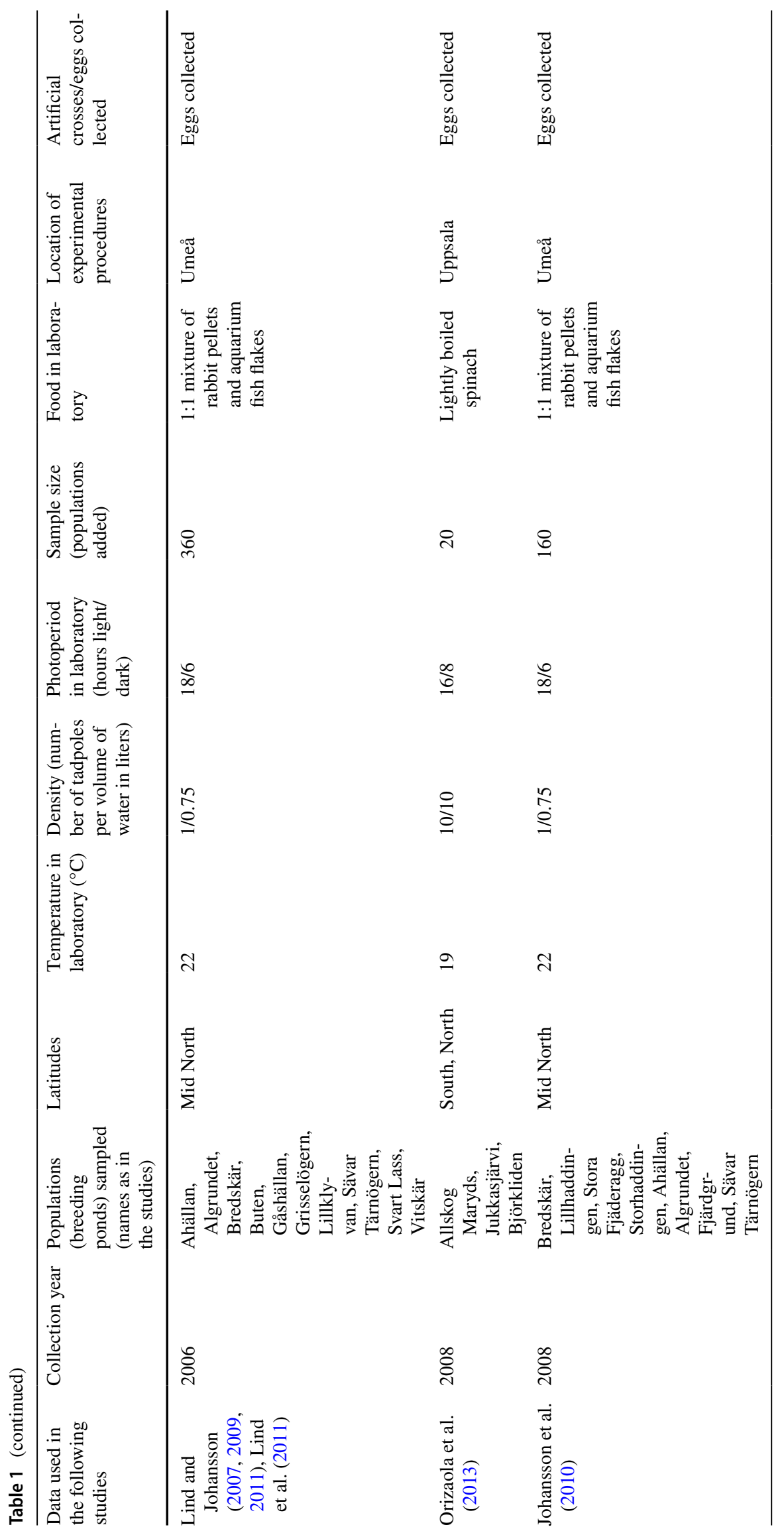


standard error (Hadfield 2010). Study ID, population, and the year $\times$ population interaction were added as random effects. The population term referred to the specific population (breeding pond) sampled in any given study (Table 1). To avoid an over-parameterized model, while still assessing the effect of potentially confounding variables, we used a combination of a pre-set model (the variables for which we had an explicit biological interest in), and a forward model selection approach (for the variables that we wanted to control for-which were related to lab specific rearing conditions). The explanatory variables for which we had explicit biological interest in (reproductive delay, latitude, and their interaction) were consequently added as fixed effects to all models we assessed. For the additional variables, that we had no explicit interest in but that potentially could confound our results, we used a forward selection approach. We used Deviance Information Criterion (DIC, Spiegelhalter et al. 2002) to select the main model. DIC is a hierarchical modeling generalization of Akaike Information Criterion (AIC). Specifically, laboratory temperature, photoperiod, food, larval density, and laboratory location were included in separate models, including their interaction with latitude. These additional variables were removed if they did not improve the fit of the model (judged as a delta DIC $>1$ ). Each of these models hence contained the added variable that we wanted to control for, its interaction with latitude, and the parameters that we had biological interest in: delay, latitude, and their interaction, as fixed effects. In the cases were the inclusion of a variable and its interaction with latitude improved the fit of the model, we further assessed the inclusion of the interaction. The final model, chosen on the basis of its DIC value, was a model containing delay, latitude, their interaction, as well as laboratory rearing temperature, as fixed effects (see Online Resource 3, Tables S3.1-S3.7 for model formulas, DIC values, and results of all the models). Inclusion of photoperiod and study location improved the fit only marginally (delta $D I C<1$ ), so these variables were not included in the final model. Southern population was set as a reference in the main model, with all other populations being compared with this population. To assess the latitude specific value of the effect of breeding delay (as indicated by the interactions between delay and latitude), we fit different versions of the same model, where the different models (otherwise identical), had a different reference latitude. We used MCMCglmm (Hadfield 2010) mixed models, in R version 3.6.0 (R Development Core Team 2019).

We chose priors that should be non-informative for the result. Hence, a flat, Gaussian prior with mean zero and a variance of $10^{10}$ was used for the fixed effects, and locally non-informative, inverse Wishart priors, with prior variance estimate set to one fourth of the total phenotypic variance (hence having a prior belief of equal weights to all variance components), and belief parameter set to 0.002 , was used for the random effects. Both represent little prior knowledge (see Online Resource 4 for more details on the specification of priors). We run at least $2 \times 10^{6}$ iterations, a burn-in of $5 \times 10^{4}$, and a thinning interval of 2000 , which resulted in effective sampling size of 1000 . The predictors were centered to a mean of 0 in order to give model estimates at the mean predictor values (Schielzeth 2010). To increase comparability, we estimated standardized regression coefficients by scaling predictors to a standard deviation of 1 . We diagnosed posterior distributions and model convergence by running three parallel chains using the Gelman-Rubin convergence criterion, and the upper 97.5 quantile of the Gelman-Rubin test statistic was below 1.2 in all cases. All autocorrelations were within the interval -0.1 and 0.1 . A precision plot did not show any major asymmetry, suggesting that there was no publication bias in our data (Online Resource 5, Fig. S5).

\section{Results}

\section{Larval period length at different latitudes}

Our results confirmed that the larval period of $R$. temporaria is shorter in northern compared to southern populations $\left(\beta=-2.36 ; 95 \% \mathrm{CI}-4.41,-0.359 ; P_{\mathrm{MCMC}}<0.02\right)$.

\section{Reproductive delay and latitude interaction}

The slope of the reproductive delay differed between the southern and mid-northern populations $(\beta=-3.38 ; 95 \% \mathrm{CI}$ $\left.-5.48,-1.29 ; P_{\mathrm{MCMC}}=0.002\right)$ and between the southern and northern populations $(\beta=-4.35 ; 95 \% \mathrm{CI}-5.78,-2.93$; $\left.P_{\text {MCMC }}<0.001\right)$. Larval period increased significantly with breeding delay in the southern populations $(\beta=2.4 ; 95 \%$ CI $0.979,3.84 ; P_{\text {MCMC }}<0.001$; Fig. 1a) and decreased in (a)

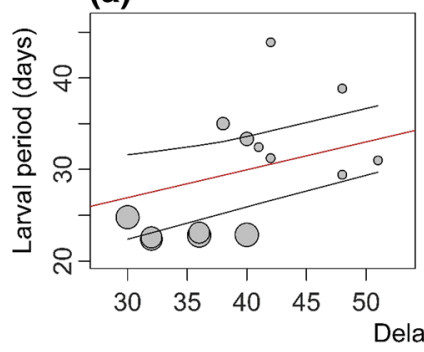

Delay (days) (b)

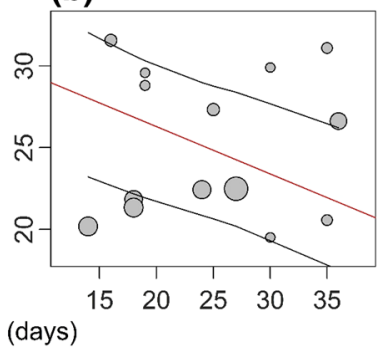

Fig. 1 The relationship between reproductive delay and larval period in $\mathbf{a}$ southern, and $\mathbf{b}$ northern populations of $R$. temporaria. The regression lines (red) are placed between the $95 \%$ confidence interval range lines (black), and are based on estimates from the model containing delay, latitude, and their interaction as fixed effects. Area of the points corresponds to the precision of the estimates $\left(1 / \mathrm{SEM}_{\text {estimate }}\right)$ 
the northern populations $(\beta=-1.94 ; 95 \% \mathrm{CI}-2.81,-1.10$; $P_{\text {MCMC }}<0.001$; Fig. 1b).

\section{Discussion}

We investigated the effects of reproductive delay in the parental generation, on the larval period in $R$. temporaria frog populations, across a latitudinal gradient in Sweden. We found that breeding delay affected offspring traits. In the north, larval period decreased with increasing reproductive delay, while the opposite was observed for the southern populations. The lack of any external environmental cues for larvae under common-garden rearing, suggests a parental origin for observed changes in larval life history traits.

Interestingly, the effect of breeding delay was of similar magnitude, but in different directions for the southern and northern populations. Specifically, a higher reproductive delay induced shorter larval period in the north, but longer larval periods in the south. In accordance with previous experimental research, which artificially postponed reproduction on mid-southern populations of $R$. arvalis and $R$. temporaria (Lindgren and Laurila 2010; Richter-Boix et al. 2014; Orizaola et al. 2016), we found a decreased larval period in response to later reproduction, in northern populations, which suggests an adaptive response to a shortened growing season. Moreover, similar to our study, Orizaola et al. (2013) found that northern populations of R. temporaria developed faster during a year with a shorter growing season, and the magnitude of change was comparable with our study (compare Fig. 1b in the present study with Fig. 3a, $\mathrm{b}$ in Orizaola et al. 2013). These results indicate that parental effects in vertebrates from time-constrained environments may act to further decrease their already short development times.

Southern $R$. temporaria populations, on the other hand, had longer larval developmental times as a response to increasing breeding delay. If the length of the growing season is sufficient, even after a delay, there may not be any reasons to expect that a breeding delay would decrease larval period. However, this does not explain the significant increase in breeding delay that we observed in our study. Previous studies have shown that delayed $R$. temporaria and $R$. arvalis tadpoles, increase their development rates, but also lower antipredator defenses (Orizaola et al. 2013, 2016), which is likely to increase predator-mediated mortality. Moreover, it has been shown that in the wild, tadpoles from southern populations of $R$. temporaria experience higher predator densities than tadpoles from northern populations (Laurila et al. 2008). Indeed, the lower predator densities and lower predator activity due to lower water temperatures may facilitate higher developmental rates in wild northern populations, as fast growth rate trades off with other life history traits and requires higher foraging activity that may lead to increased mortality (Gotthard et al. 1994; Gotthard 2000, 2008; Laurila et al. 2006, 2008). Hence, the increase in the larval period in the southern populations observed in our study could be an indication of such an adaptive tradeoff, i.e., the breeding delay affects larval period in the southern populations by modulating a third, unmeasured variable, such as growth rate/mortality.

Predation on amphibians may be size-, or stage-specific (Werner 1986; Kaplan 1992; Urban 2007), meaning that under certain conditions, longer or shorter larval periods may facilitate escape from tadpole stage-specific predators, like dragonfly larvae, and consequentially be evolutionary advantageous. Therefore, increased larval period by southern $R$. temporaria populations could be adaptive despite the delay in reproduction, since longer larval periods may be caused by lower tadpole activity, as a predator avoidance strategy. In addition, as ectotherms, dragonfly larvae are more active at higher temperatures, and water in the southern locations will likely become warmer sooner than in the north. Therefore, the appearance of tadpoles in these ponds will coincide with already highly active dragonfly larvae. Tadpoles are exposed for a longer time to highly active dragonfly larvae in the south, compared to in the north, when the breeding season has been delayed. As a consequence, southern populations could show a stronger response of reduced activity and development rate to avoid more active predators in a late reproductive season.

Studies on other organisms have shown latitudinal specific parental effects on growth and performance, and these effects often result in evolutionary trade-offs (e.g., insects: Mousseau and Dingle 1991; fish: Johnston and Leggett 2002; reptiles: Sinervo 1990; humans: Staples et al. 2010). For example, lizards from northern latitudes produce smaller eggs that develop faster, hatchlings that grow faster, but also juveniles with slower sprint speeds, potentially making them more vulnerable to predators (Sinervo 1990). However, the production of small eggs in northern populations could still maximize fitness, if larger eggs experienced higher mortality, as selection may maximize maternal fitness at the cost of offspring fitness (Marshall and Uller 2007). For example, females that reproduce multiple years may limit investment in eggs, and produce low-quality eggs in case of temporarily unfavorable environmental conditions. In our study, this would mean that females produced slow-developing eggs in years with delayed reproduction, if these years were perceived as having unfavorable environmental conditions.

A caveat to our study is that our data was extracted from previous studies, rather than being collected with a fully standardized methodology, as would be the case for experimental data. Hence, some of the variables in our data, such as laboratory temperature, food and latitude, were somewhat confounded. Most of the confounds in our 
data are caused by data being included from two research groups, one in Uppsala, and one in Umeå (both in Sweden). However, we do not see this as being problematic in our study, because our main results and conclusions were based on differences between the northern and southern populations, which were investigated only by the Uppsala based research group. Further, in addition to parental effects, alternative explanations of our results are possible. For example, delayed breeding could result in carry-over effects associated with parental physiological stress. In such a case, southern $R$. temporaria populations could be less able to cope with conditions associated with reproductive delay than northern populations, and produce slower developing offspring. Mother-offspring stress hormone transfer through egg yolk is a well-known phenomenon (Sheriff and Love 2013), and previous studies have suggested that climate and weather conditions may influence stress hormone levels in vertebrates (Sheriff et al. 2012). Moreover, previous research on R. temporaria found that southern populations had higher corticosterone levels in response to stress than northern populations, which in turn, decreased growth and development (Dahl et al. 2012). Therefore, it is possible that egg-mediated hormonal changes in offspring could influence the larval period in southern populations of $R$. temporaria.

\section{Conclusions}

Our results suggest that local adaptation to a short growing season has resulted in potentially adaptive parental effects of delayed breeding time in northern $R$. temporaria populations. We suggest that many of the latitudinal differences in parental effects documented may potentially be explained either by differences in life-history trade-offs, or by the evolution of sensitivity to latitude-specific cues, presenting a fruitful avenue for further research.

Acknowledgements Open access funding provided by Stockholm University. We would like to thank Alejandro Gonzalez-Voyer, Joacim Näslund, Richard Svanbäck, Bertil Borg, and two anonymous reviewers for comments on the manuscript, as well as all the authors that answered our questions regarding studies incorporated in the meta-analysis: Beatrice Lindgren, Juha Merilä, Katja Räsänen, and Celine Teplitsky. This research was supported by The Swedish Research Council grant to B.R.

Author contribution statement PKR, AL and BR conceived and designed the study. PKR searched for the data. AL, MIL and AR-B provided data. PKR and BR analyzed the data. PKR wrote the first draft of the manuscript. All authors commented on the final draft of the manuscript.

Funding This study was funded by Vetenskapsrådet (2013-5064).

\section{Compliance with ethical standards}

Conflict of interest The authors declare that they have no conflict of interest.

Formal consent For this type of study formal consent is not required.

Open Access This article is licensed under a Creative Commons Attribution 4.0 International License, which permits use, sharing, adaptation, distribution and reproduction in any medium or format, as long as you give appropriate credit to the original author(s) and the source, provide a link to the Creative Commons licence, and indicate if changes were made. The images or other third party material in this article are included in the article's Creative Commons licence, unless indicated otherwise in a credit line to the material. If material is not included in the article's Creative Commons licence and your intended use is not permitted by statutory regulation or exceeds the permitted use, you will need to obtain permission directly from the copyright holder. To view a copy of this licence, visit http://creativecommons.org/licenses/by/4.0/.

\section{References}

Arnett AE, Gotelli NJ (1999) Geographic variation in life-history traits of the ant lion, Myrmeleon immaculatus: evolutionary implications of Bergmann's rule. Evolution 53:1180-1188

Bernardo J (1996) Maternal effects in animal ecology. Am Zool $36: 83-105$

Berven KA (1982) The genetic basis of altitudinal variation in the wood frog Rana sylvatica. I. an experimental analysis of life history traits. Evolution 36:962-983

Conover DO, Present TM (1990) Countergradient variation in growth rate: compensation for length of the growing season among Atlantic silversides from different latitudes. Oecologia 83:316-324

Conover DO, Schultz ET (1995) Phenotypic similarity and the evolutionary significance of countergradient variation. Trends Ecol Evol 10:248-252

Dahl E, Orizaola G, Winberg S, Laurila A (2012) Geographic variation in corticosterone response to chronic predator stress in tadpoles. $\mathrm{J}$ Evol Biol 25:1066-1076

Dey S, Proulx SR, Teotonio H (2016) Adaptation to temporally fluctuating environments by the evolution of maternal effects. PLoS Biol 14:e1002388

Donelan SC, Trussell GC (2018) Parental and embryonic experiences with predation risk affect prey offspring behaviour and performance. Proc Royal Soc B Biol Sci 285:20180034

Du WG, Warner DA, Langkilde T, Robbins T, Shine R (2010) The physiological basis of geographic variation in rates of embryonic development within a widespread lizard species. Am Nat 176:522-528

Dury GJ, Wade MJ (2019) When mother knows best: a population genetic model of transgenerational versus intragenerational plasticity. J Evol Biol 33:127-137

Eckerström-Liedholm S, Sowersby W, Gonzalez-Voyer A, Rogell B (2017) Time-limited environments affect the evolution of eggbody size allometry. Evolution 71:1900-1910

Gillooly JF, Charnov EL, West GB, Savage VM, Brown JH (2002) Effects of size and temperature on developmental time. Nature 417:70

Gosner KL (1960) A simplified table for staging anuran embryos and larvae with notes on identification. Herpetologica 16:183-190

Gotthard K (2000) Increased risk of predation as a cost of high growth rate: an experimental test in a butterfly. J Anim Ecol 69:896-902 
Gotthard K (2008) Adaptive growth decisions in butterflies. AIBS Bull $58: 222-230$

Gotthard K, Nylin S, Wiklund C (1994) Adaptive variation in growth rate: life history costs and consequences in the speckled wood butterfly, Pararge aegeria. Oecologia 99:281-289

Hadfield JD (2010) MCMC methods for multi-response generalized linear mixed models: the MCMCglmm R package. J Stat Softw 33:1-22

Janssens L, Stoks R (2018) Rapid larval development under time stress reduces adult lifespan through increasing oxidative damage. Funct Ecol 32:1036-1045

Johansson F, Stoks R, Rowe L, De Block M (2001) Life history plasticity in a damselfly: effects of combined time and biotic constraints. Ecology 82:1857-1869

Johansson F, Lederer B, Lind MI (2010) Trait performance correlations across life stages under environmental stress conditions in the common frog, Rana temporaria. PLoS ONE 5:e11680

Johnston TA, Leggett WC (2002) Maternal and environmental gradients in the egg size of an iteroparous fish. Ecology 83:1777-1791

Kaplan RH (1992) Greater maternal investment can decrease offspring survival in the frog, Bombina orientalis. Ecology 73:280-288

Kirkpatrick M, Lande R (1989) The evolution of maternal characters. Evolution 43:485-503

Kuijper B, Hoyle RB (2015) When to rely on maternal effects and when on phenotypicplasticity? Evolution 69:950-968

Kuzmin S, Ishchenko V, Tuniyev B, Beebee T, Andreone F, Nyström P, Anthony BP, Schmidt B, Ogrodowczyk A, Ogielska M, Bosch J, Miaud C, Loman J, Cogalniceanu D, Kovács T, Kiss I (2009b) Rana temporaria (errata version published in 2016). IUCN Red List Threat Species 2009b:e.T58734A86470817. https:// doi.org/10.2305/IUCN.UK.2009.RLTS.T58734A11834246.en (accessed 2017-12-17)

Lankford TE, Billerbeck JM, Conover DO (2001) Evolution of intrinsic growth and energy acquisition rates. II. Trade-offs with vulnerability to predation in Menidia menidia. Evolution 55:1873-1881

Laugen AT, Laurila A, Räsänen K, Merilä J (2003) Latitudinal counter gradient variation in the common frog (Rana temporaria) development rates-evidence for local adaptation. J Evol Biol 16:996-1005

Laurila A, Pakkasmaa S, Merilä J (2001) Influence of seasonal time constraints on growth and development of common frog tadpoles: a photoperiod experiment. Oikos 95:451-460

Laurila A, Karttunen S, Merilä J (2002) Adaptive phenotypic plasticity and genetics of larval life histories in two Rana temporaria populations. Evolution 56:617-627

Laurila A, Pakkasmaa S, Merilä J (2006) Population divergence in growth rate and antipredator defenses in Rana arvalis. Oecologia 147:585-595

Laurila A, Lindgren B, Laugen AT (2008) Antipredator defenses along a latitudinal gradientin Rana temporaria. Ecology 89:1399-1413

Levinton JS (1983) The latitudinal compensation hypothesis: growth data and a model of latitudinal growth differentiation based upon energy budgets. I. Interspecific comparison of Ophryotrocha (Polychaeta: Dorvilleidae). Biol Bull 165:686-698

Li T, Cao P, Bei YJ, Du WG (2018) Latitudinal and temperaturedependent variation in embryonic development rate and offspring performance in a freshwater turtle. Physiol Biochem Zool 91:673-681

Liess A, Guo J, Lind MI, Rowe O (2015) Cool tadpoles from Arctic environments waste fewer nutrients-high gross growth efficiencies lead to low consumer-mediated nutrient recycling in the North. J Anim Ecol 84:1744-1756

Lind MI, Johansson F (2007) The degree of adaptive phenotypic plasticity is correlated with the spatial environmental heterogeneity experienced by island populations of Rana temporaria. J Evol Biol 20:1288-1297

Lind MI, Johansson F (2009) Costs and limits of phenotypic plasticity in island populations of the common frog Rana temporaria under divergent selection pressures. Evolution 63:1508-1518

Lind MI, Johansson F (2011) Testing the role of phenotypic plasticity for local adaptation: growth and development in time-constrained Rana temporaria populations. J EvolBiol 24:2696-2704

Lind MI, Ingvarsson PK, Johansson H, Hall D, Johansson F (2011) Gene flow and selection on phenotypic plasticity in an island system of Rana temporaria. Evolution 65:684-697

Lind MI, Zwoinska MK, Andersson J, Carlsson H, Krieg T, Larva T, Maklakov AA (2019) Environmental variation mediates the evolution of anticipatory parental effects. bioRxiv 606103. https ://doi.org/10.1101/606103

Lindgren B, Laurila A (2010) Are high-latitude individuals superior competitors? A test with Rana temporaria tadpoles. Evol Ecol $24: 115-131$

Marshall DJ, Uller T (2007) When is a maternal effect adaptive? Oikos 116:1957-1963

Merilä J, Laurila A, Laugen AT, Räsänen K, Pahkala M (2000) Plasticity in age and size at metamorphosis in Rana temporariacomparison of high and low latitude populations. Ecography 23:457-465

Merilä J, Laurila A, Lindgren B (2004) Variation in the degree and costs of adaptive phenotypic plasticity among Rana temporaria populations. J Evol Biol 17:11321140

Mousseau TA, Dingle H (1991) Maternal effects in insect life histories. Annu Rev Entomol 36:511-534

Mousseau TA, Fox CW (eds) (1998a) Maternal effects as adaptations. Oxford University Press, Oxford

Mousseau TA, Fox CW (1998b) The adaptive significance of maternal effects. Trends EcolEvolution 13:403-407

Mousseau TA, Uller T, Wapstra E, Badyaev AV (2009) Evolution of maternal effects: past and present. Philos Trans R Soc B: Biol Sci 364:1035-1038

Orizaola G, Dahl E, Nicieza AG, Laurila A (2013) Larval life history and anti-predator strategies are affected by breeding phenology in an amphibian. Oecologia 171:873-881

Orizaola G, Richter-Boix A, Laurila A (2016) Transgenerational effects and impact of compensatory responses to changes in breeding phenology on antipredator defenses. Ecology 97:470-2478

Palo JU, Ohara RB, Laugen AT, Laurila A, Primmer CR, Merilä J (2003) Latitudinal divergence of common frog (Rana temporaria) life history traits by natural selection: evidence from a comparison of molecular and quantitative genetic data. Mol Ecol 12:1963-1978

Phillimore AB, Hadfield JD, Jones OR, Smithers RJ (2010) Differences in spawning date between populations of common frog reveal local adaptation. PNAS 107:82928297

R Development Core Team (2019) R: a language and environment for statistical computing. R Foundation for Statistical Computing, Vienna

Räsänen K, Kruuk LEB (2007) Maternal effects and evolution at ecological time-scales. Funct Ecol 21:408-421

Richter-Boix A, Teplitsky C, Rogell B, Laurila A (2010) Local selection modifies phenotypic divergence among Rana temporaria populations in the presence of gene flow. MolEcol 19:716-731

Richter-Boix A, Orizaola G, Laurila A (2014) Transgenerational phenotypic plasticity links breeding phenology with offspring lifehistory. Ecology 95:2715-2722

Rogell B, Hofman M, Eklund M, Laurila A, Höglund J (2009) The interaction of multiple environmental stressors affects adaptation to a novel habitat in the natterjack toad Bufo calamita. J Evol Biol 22:2267-2277 
Rossiter M (1996) Incidence and consequences of inherited environmental effects. Annu Rev Ecol Syst 27:451-476

Schielzeth H (2010) Simple means to improve the interpretability of regression coefficients. Methods Ecol Evol 1:103-113

Sheriff MJ, Love OP (2013) Determining the adaptive potential of maternal stress. EcolLett 16:271-280

Sheriff MJ, Wheeler H, Donker SA, Krebs CJ, Palme R, Hik DS, Boonstra R (2012) Mountain-top and valley-bottom experiences: the stress axis as an integrator of environmental variability in arctic ground squirrel populations. J Zool 287:65-75

Sinervo B (1990) The evolution of maternal investment in lizards: an experimental and comparative analysis of egg size and its effects on offspring performance. Evolution 44:279-294

SMHI (2017) Swedish Meteorological and Hydrological Institute. https://www.smhi.se/kunskapsbanken/meteorologi/var-1.1080. Accessed 18 Dec 2017

Spiegelhalter DJ, Best NG, Carlin BP, Van Der Linde A (2002) Bayesian measures of model complexity and fit. J R Stat Soc B 64:583-639
Staples J, Ponsonby AL, Lim L (2010) Low maternal exposure to ultraviolet radiation in pregnancy, month of birth, and risk of multiple sclerosis in offspring: longitudinal analysis. BMJ 340:c1640

Tang J, He H, Chen C, Fu S, Xue F (2017) Latitudinal cogradient variation of development time and growth rate and a negative latitudinal body weight cline in a widely distributed cabbage beetle. PLoS ONE 12:e0181030

Trussell GC (2002) Evidence of counter gradient variation in the growth of an intertidal snail in response to water velocity. Mar Ecol Prog Ser 243:123-131

Uller T, Nakagawa S, English S (2013) Weak evidence for anticipatory parental effects in plants and animals. J Evol Biol 26:2161-2170

Urban MC (2007) Risky prey behavior evolves in risky habitats. PNAS 104:14377-14382

Werner EE (1986) Amphibian metamorphosis: growth rate, predation risk, and the optimal size at transformation. Am Nat 128:319-341

Zuo W, Moses ME, West GB, Hou C, Brown JH (2012) A general model for effects of temperature on ectotherm ontogenetic growth and development. Proc R Soc B Biol Sci 279:1840-1846 